\title{
Mitigating the Challenges Related to the Implementation of the Convention on Biological Diversity in Ghana
}

\author{
Thomas Prehi Botchway ${ }^{1} \&$ Ishmael K. Hlovor ${ }^{2}$ \\ ${ }^{1}$ Law School, Chongqing University, Shapingba, Chongqing, China \\ ${ }^{2}$ Wisconsin International University College, Ghana \\ Correspondence: Thomas Prehi Botchway, Law School, Chongqing University, Shapingba District, Chongqing, \\ 400044, China. E-mail: abeikuprehi@yahoo.com; prehionline@gmail.com
}

\author{
Received: March 31, $2019 \quad$ Accepted: May 6, $2019 \quad$ Online Published: May 30, 2019 \\ doi:10.5539/jsd.v12n3p91 URL: https://doi.org/10.5539/jsd.v12n3p91
}

\begin{abstract}
In our world today, the control over and the use of a country's natural resources (and the biological diversity of which they are a part) usually present a lot of challenges for both policy makers and implementing agencies and institutions. These challenges range from weak institutional capacities and technocratic hurdles to opposition from local communities for whom policies may be meant for. However, if such challenges are effectively mitigated, large prospects usually associated with the sustainable use and management of these natural resources may be realised. In this article, based on intensive interview of experts and critical review of official reports and policy documents, we identify a number of challenges associated the implementation of the Convention on Biological Diversity (CBD) in Ghana and recommend ways of addressing these challenges.

The study finds that there is usually a wide knowledge and information gap on issues related to biodiversity in Ghana. Moreover, there is inadequate funding which also leads to the inability to retain relevant experts. In addition, there is the complex nature of implementing multilateral environmental agreements in Ghana and the lack of adequate publicity on the essence of the CBD. Key among the recommendations we make are effectively engaging civil society organisations on issues of biodiversity conservation and sustainable development; the enhancement of Alternative Livelihood Projects (EnALPs); stringent enforcement of punitive and preventive measures and; the implementation of finance-generating biodiversity services.
\end{abstract}

Keywords: Ghana, convention on biological diversity (CBD), implementation, sustainable development, biodiversity

\section{Introduction: Implementation of the CBD in Ghana (Note 1)}

The implementation of the Convention on Biological Diversity (CBD) in Ghana reveals a mixed record; whereas improvement is seen in some areas, the situation in others seem unchanged, while other areas also continue to witness deterioration in the face of the unceasing efforts by the duty bearers - a scenario that can be attributed partly to the usually clumsy implementation of sectoral socio-economic development policies. In all this, in an effort to meet its international obligation and also to achieve its national goals of sustainable development, successive governments in Ghana have always pursued both courses - implementing the requirement of the CBD as much as possible but balancing the domestic needs of the citizens at all times. (Botchway, 2019b) For instance through the Ghana Shared Growth Development Agenda (GSGDA, 2010-2013), the country sought to promote science, technology, the maintenance environmental quality and the integration of environmental concerns into development policies. The introduction of the Forest and Wildlife Policy (1994), Wildfire Policy, National Bio-safety in biotechnology guidelines, as well as the Fisheries Act (2002) and the Community Resource Management Areas (CREMA) - which targets the improvement of natural resource management capacity of fringe communities in off-reserve wildlife conservation, are all aimed at biodiversity conservation even as they promote sustainable development. The country currently has 27 CREMAs of which 19 are certified.

Studies have shown that the production of ecosystem goods and services in Ghana has reduced due mainly to the loss of fishing grounds, grazing lands, farmlands, energy sources, watersheds and scarcity of water sources. In addition, there is a general decline in biodiversity. This notwithstanding, there are also some positive developments that have contributed to encouraging increases in the quality of biodiversity in the country. 
Consequently, available research on Ghana have identified the major threats to biodiversity in Ghana to include land-use conversions, habitat degradation, pollution, over-exploitation, invasive alien species, climate change, predation, wild fires and poaching, as well as over-harvesting of genetic resources and misapplication of chemicals. (CBD Secretariat, nd)

Ghana has an active Sector Working Groups (SWG) structure that includes a wide range of civil society organizations, private sector entities and development partners and all these entities aim at helping address conflicting objectives, increasing multi-sector ownership, and also aligning the policy making within national development and poverty reduction strategies. In so doing, these working groups help in reducing the transaction costs associated with the redundancies in environmental planning measures as well as inefficient consultation processes undertaken independently by each sector. (Secretariat of the Convention on Biological Diversity (SCBD), 2010)

Over the years, stakeholders in Ghana, using the Strategic Environmental Assessment (SEA) have evaluated the environmental risks as well as the prospects connected to the strategy's policies with the view to identifying suitable procedures so as to safeguard rigorous environmental management as a means of developing sustainable growth and poverty reduction in the country. Consequently, the SEA approach has become prominent and this in turn has led to an improvement in biodiversity conservation activities and budgeting in the country though several challenges still remain. The SEA has also impacted positively on the attitudes of officials responsible for planning and budgeting, thereby inspiring them to pursue the mutual benefits that usually accompanies the integration of environmental issues in policy planning and programming. The result is the merging of environmental policies into the country's various development plans and legislative instruments.

Accordingly, Ghana, as at 2010 was classified among the few developing countries in the world that has been able to "successfully" integrate "the role played by environmental systems and biodiversity" within its development policies "by linking them to green indicators." These indicators thus reflect the role and condition of ecosystem goods and services in the country and consequently help in adjusting the country's strategies and second generation poverty reduction strategy papers (PRSPs) to include clear environmental objectives. (SCBD, 2010, p. 63)

The establishment of the Forest Plantation Development Fund Act and other environmental-related funds have over the years supported the much-needed investments in planted forests, ecological restoration, and also ensured the conservation of biodiversity. Consequently, Ghana has a number of Globally Significant Biodiversity Area (GSBAs). These GSBAs are legally established areas identified within the existing forest reserve system and consists of a potential network of 30 forest reserves that are proposed for either full (11 reserves) or partial (19 reserves). These are meant for the protection and provision of global security for floristic diversity and include the Southern Dry Forests and the Provenance Protection Areas of the country. (World Bank, 2006)

Arguably, efforts at biodiversity conservation and protection in Ghana predate the introduction of the CBD. Moreover, though most of Ghana's forest reserves were established through negotiation with chiefs and traditional authorities in the 1930s, the first formal forest policy was prepared in 1948. This policy provided for the conservation and protection of the forest reserve estate. It must also be noted that the 1927 Forest Ordinance/the Native Authorities Ordinance also enabled authorities to constitute forest reserves under their bye laws. After ratifying the CBD, the country also introduced the 1994 Forest and Wildlife Policy which targets the conservation of biodiversity and also promotes sustainable development by encouraging efficient management of the nation's forest and wildlife resources. It also aims at maintaining environmental quality and the perpetual flow of optimum benefits to all segments of the Ghanaian society.

Additionally, in order to enhance the conservation of biodiversity and to achieve the targets of the CBD namely conservation of biodiversity, sustainable use of biological resources, and access and benefit sharing, Ghana has over the years been implementing several strategic plans and policies among which are the Coastal Zone Management Indicative Plan (1990), National Environmental Action Plan (1994), the Draft Integrated Coastal Zone Plan, and the Coastal Zone Profile of Ghana both introduced in 1998, and the National Oil Spill Contingency Plan (2002), and the Environmental sensitivity map of the coastal areas of Ghana $(1999,2004)$. For instance, in order to reduce the use of forestry products as fuel (firewood), the country has been promoting the use of Liquefied Petroleum Gas (LPG) which is comparatively "healthier, safer and cleaner" in rural and semi-urban areas. The State consequently distributed about "17,000 cylinders, stoves and accessories under the Rural LPG Promotion Programme (RLPGPP).”(Government of Ghana (GoG), 2017, p. 91)

The construction of various sea defense projects along the country's coasts has also proven useful in mitigating excessive coastal erosion and land degradation. Various efforts have also been made to enhance public awareness 
and sensitization on the proper and sustainable use of ecosystem resources. Consequently, since the inception of Ghana's fourth Republic in 1992 and the consequent ratification of the CBD, the country has made tremendous efforts toward realizing the goals of sustainable development while at the same time meeting the CBD goals. Thus, in addition to the CBD and its related protocols (the Cartagena Protocol on Bio-Safety, and the Nagoya Protocol on Access and Benefit-Sharing [which the country is yet to ratify]), the country at the international level has also ratified a number of international conventions and protocols such as the United Nations Framework Convention on Climate Change (UNFCCC) in 1995. It also became a signatory to the Kyoto protocol in 2003 and the Basel Convention, UN Convention on Desertification, etc. and has actively participated in several discussions on international environmental governance.

The country has also created the Environmental Protection Agency (EPA) which is a supervisory and implementing agency with powers to prosecute and ensure the conservation of biodiversity and all issues of environmental concern. This alongside the creation the Ministry of Environment, Science and Technology, as well as the Ministry of Lands and Natural Resources, which are mandated to ensure the development of policies on sustainable development and appropriate land and natural resources use, as well as the several schemes and programmes that have been implemented over the years have impacted positively on sustainable development in the country.

Furthermore, the country, in order to indicate its strong commitment to environmental issues and in achieving the CBD targets has over the years been subjecting its medium term development frameworks such as the Ghana Poverty Reduction Strategy (2003-2006), Growth and Poverty Reduction Strategy (2006-2009) and the GSGDA (2010-2013) to SEA through the National Development Planning Commission (NDPC). These major frameworks have been ensuring the prioritization of water and sanitation, health, housing, education, reduction of disparity in the distribution of national resources, as well as ensuring the sustainable use of natural resources through application of science, technology and innovation.

The effort to pass the Right to Information Bill and the existing Whistle Blower's Act has further ensured accountability and transparency in governance and also reduced corruption. These Acts consequently ensure the efficient use of resources and enhance sustainable development. Citizens are also encouraged by the laws to critically assess the government's performance on the implementation of relevant policies such as those outlined in the CBD which in the long run promotes the country's sustainable development agenda.

The establishment of the Green Energy Fund which gives financial supports to the generation of green energy in homes has also had a positive impact on the country's efforts at biodiversity conservation. Moreover, there exists in Ghana a tax free policy for the importation of solar energy panels. (Ministry of Environment, Science and Technology (MEST), 2011) This means a reduction in the use of energy sources that are quite harmful to the environment and biodiversity.

To ensure the protection of forestry resources, the government of Ghana and its development partners has over the years initiated several policies and multilateral environmental agreements (MEAs) that are in line with the CBD objectives. An example of such agreements is the Natural Resources and Environmental Governance (NREG) programme which prioritizes activities and time-bound targets in order to "reverse the persistent trend of high environmental degradation in a coordinated and sustainable manner." (Adutwum, 2010, p. 36) Moreover, there is the Voluntary Partnership Agreement (VPA) which was initiated between the Government of Ghana and the European Union (EU). The VPA aims at ensuring that timber products from Ghana are obtained from certified sources and that their production does not cause unnecessary harm to other forestry biodiversity as advocated by the CBD.

In order to achieve Ghana's CBD targets - namely conservation of biodiversity, sustainable use of biological resources, and access and benefit sharing, efforts have also been made to promote the various pillars of sustainable development namely the social, economic and environmental pillars of sustainable development. These efforts have consequently been reflected in the goals of the country's National Environmental Action Plan (NEAP), the GSGDA, National Sustainable Development Strategies (NSDSs), as well as the Millennium Development Goals (MDGs) and have been generally integrated into policy and planning in various sectors of the economy. Emphasis has over the years been on promoting pro-poor approaches and sustainable urban management that enhances sustainable consumption and production in the long run.

It is evident from the numerous environmental-friendly policies that Ghana, in order to meet its double-edged obligation: socio-economic development and biodiversity conservation (environmental protection), is making a gradual transition to a green economy. Thus, various governments have made efforts to reshape and redirect environmental policies and investments while at the same time improving spending in renewable energy, clean 
technologies, green transportation, water services, sustainable agriculture and forests, as well as waste management. These efforts, according to experts, does not only seek coherence between the three pillars of sustainable development, but also aims at mitigating other developmental challenges such as climate change and subsequently benefits the poor.

One key instrument that has over the years ensured the proper management of forest resources in Ghana is the Timber Resource Management Act of Ghana, 1999 which establishes the Timber Utilization Contract (TUC). The TUC ensures local participation by requiring that the opinions and wishes of the community that owns the lands in the area under a given contract should be sought before operations begin. Thus, the contractor must submit a Contract Operation Plan that addresses thoroughly the harvesting operation and its environmental impacts as well as how the local communities will benefit from the operations. Consequently, land owners within the operations area have the right to reject the contract if they deem it inimical to the environment and the community as a whole. They can also demand compensation for any damage caused by the operations, especially felling timber.

Aside the several international MEAs, Ghana has also ratified numerous Regional Conventions within the African continent and the sub-region, most of which, according to recent studies have "failed because of inadequate financial mechanism to facilitate implementation." (Okley, 2004, p. 47) Key among them is the 1968 African Convention on the Conservation of Nature and Natural Resources and the Bamako Convention on the Ban of Import into Africa and the Control of Transboundary Movement and Management of Hazardous Wastes within Africa, 1991.

With regards to the place and use of indigenous knowledge, an interviewee has argued that "it is impossible" to promote biodiversity conservation and for that matter the CBD "without them." This international relations and environmental governance expert is of the view that though in most cases indigenous knowledge may be lacking scientific backing, the rationale for such knowledge is basically the conservation of biodiversity. Thus, through some practices, customs and taboos, the indigenous people "allow the environment the free-way to rejuvenate." (Interview I. R., 2018) Experts also affirm the underlining principle of Article 8 (j) of the CBD by arguing that indigenous "people have to own the programme." The assumption is that "without the indigenous ownership of the programme, there is resistance." Consequently, the formulation of a CBD-related programme and any MEA must take into consideration the identification and incorporation of indigenous and informal structures and rules of the community that are more "resilient" and "effective in affecting social order." (Interview I. R., 2018)

In a related matter, regarding indigenous peoples' attitude to biodiversity conservation and the CBD, it has been asserted that:

Changing attitudes is a long term programme. You don't just go in there and try to dictate... You try to provide stimuli that will allow them naturally to see why it is more advisable to shift from one form of practice... to a more sustainable farming practice. (Interview I. R., 2018)

Experts also believe that the involvement of the indigenous people in the implementation of the CBD is "extremely crucial." The argument is that these people "have the local knowledge... understand the environment better....They have that kind of knowledge which researchers and social scientists, or even scientists may not necessarily possess." (Interview P. P., 2018) Thus, their involvement in the implementation process will ensure that experts can tap into their knowledge in managing the biodiversity sites effectively.

\section{Research Method}

The study primarily adopts a qualitative approach and the analyses are based on the results from the intensive interview of experts in three interrelated fields of study as well as critical review of several official reports and policy documents. The experts engaged in the study included an International Relations and Global Governance Expert, a Public Policy Analyst (whose study focuses mining and natural resources extraction policies in Ghana) and an International Law Expert. These individuals were interviewed on relevant issues that relate to the implementation of internationally accepted environmental policies and agreements in Ghana (particularly, the CBD). As practitioners and academics, the study sought to seek their perspectives on what the major challenges have been as far as the implementation of the CBD in Ghana is concerned. Each interview lasted for a minimum of thirty-five minutes and a maximum of one hour-five minutes.

Moreover, official reports on the implementation of CBD and its related policies were carefully analyzed. These include the various national reports that the country has submitted to the Secretariat of the CBD as well as the country's National Biodiversity Strategy and Action Plan. The official documents consequently include those authored by several ministries, departments and agencies that are involved in the implementation of the country's 
responsibility under the CBD such as the Ministry of Environment, Science and Technological Innovation, Ministry Lands and Natural Resources, National Development Planning Commission, Forestry Commission, etc. Eventually, based on the challenges pointed out by the experts and as revealed in the numerous official reports and documents, the study recommends some useful ways of mitigating these challenges.

\section{Theoretical Framework}

The study adopts policy implementation theory as basis for analysis. Policy Implementation became an important subfield among social scientist following the work of Pressman and Wildavsky (1973). According to Pressman and Wildavsky (1984, p. xxiii), policy implementation is "a process of interaction between the setting of goals and actions geared to achieve them." Mazmanian and Sabatier (1983, pp. 20-21) see policy implementation as the carrying out of a basic policy decision, usually incorporated in a statute, but which can also take the form of important executive orders or court decisions. In the words of Paudel $(2009$, p. 36) "Implementation literally means carrying out, accomplishing, fulfilling, producing or completing a given task." According to him, "implementation can be conceptualized as a process, output and outcome." Implementation is a process involving decisions and actions aimed at putting the intent of law or policies into effect. It may also be seen as an output measuring the level of satisfaction of policy goals. Implementation also means outcome implies important changes in the problem the policy is intended to address. (Paudel, 2009, p. 36)

Implementation of environmental law or international conventions can be seen from the three dimensions outlined by Paudel (2009). However, this paper focuses on implementation as a process. The focus is on the series of activities, decisions and actions aiming at giving effect to the intent of the CBD in Ghana and what can be done to improve CBD implementation in the country.

Every international agreement needs to be domesticated in the municipality/State in order to have effect. The process of trying to implement internationally agreed convention can be faced with many challenges within the domestic setting. Implementation of international agreements in developing countries normally follows a top-down model of policy implementation. Thus, many third world governments enter into international agreements before building domestic institutions and support for implementation. This paper, therefore, discusses the CBD within the context of the top-down model proposed by Van Meter and Van Horn (1975). The model was built on the causes of implementation failure identified by Kaufman (1973).

According Kaufman (1973, p. 2), implementation failure occurs when "subordinates don't know what their superiors want, they can't do what their superiors want, or they refuse to do what their superiors want." In the view of Van Meter and Van Horn (1975), the problems are related to problems of communication, capacity and implementer disposition. The model consists of six main issue areas or variables. These include the significance of objectives, policy resources, inter-agency or organizational communication and enforcement activities, the nature of the implementing agencies, the socio-economic and political environment and the disposition of policy implementers. The six variables offer benchmark for assessment of policy implementation in a holistic manner.

This paper focuses on three of the variables identified by Van Meter and Van Horn (1975). These are significance of policy objectives, policy resources and disposition of policy implementers. The paper consequently assesses the clarity of the CBD objectives to implementers and the public; the level of resource committed to implementation of policy; and the general commitment from key actors in the implementation process. This is not to deny the relevance of the other variables, but rather to achieve a deep insight into these three key variables.

\section{Challenges Facing the Implementation of the CBD in Ghana}

Studies have shown that the current pattern of development in Ghana actually puts a lot of stress on the environment. Estimates show that "the total economic cost of poor environmental management and sanitation" in the country is about 10\% of its GDP. (International Monetary Fund (IMF), 2012, p. xiv) Such studies eventually serve as a reminder for the country to do even more to tackle the challenges posed to its natural environment and biodiversity. However, efforts aimed at mitigating these challenges are also usually hindered by a number of factors. This section identifies some of these challenges in Ghana.

\subsection{The Knowledge and Information Gap}

In a country where the status of biological diversity knowledge and information at the ecosystem, species and gene levels are generally diffused, incomplete and inaccurate (Ministry of Environment and Science (MoES), 2002), putting in place effective measures to address the targets of the CBD would certainly be a challenge. Consequently, in Ghana today, despite the existence of several legal instruments regulating various environmental and biological diversity-related activities, the country still lacks the ability to effectively conserve 
and manage biodiversity largely because of the non-existence of a single comprehensive legislation that can effectively regulate and coordinate the country's vast natural and biological resources. Accordingly, as far as Ghana's attempts at biodiversity conservation and sustainable development are concerned, notwithstanding the several Acts of Parliament, legislative instruments and previous military decrees, there are still gaps in both the legislative and institutional framework and this impact negatively on the implementation of key policy targets of the CBD in the country. There are also limited understanding on the details of MEAs and "wide knowledge gaps" in "all taxonomic groups" particularly among the citizens. (Hackman, 2014, p. 69) In addition to this is the problem of inadequate data and information system, as well as limited public awareness and education.

\subsection{Inadequate Funding and Inability to Retain Experts}

Other factors that impede effective implementation are lack of qualified personnel and expertise to assist in policy formulation - a situation which is closely linked to the acute shortage of funding for the implementation of the CBD and its related projects. Thus, though the CBD-related expertise may be lacking in some fields, even in cases where the required experts are available, the lack of adequate funding to support the implementation of the projects in question means the inability to retain these experts and to engage their services for a long time. These include bird, mammal, and wetland specialists, etc. and ecologists such as marine ecologist or freshwater ecologist and plant or terrestrial ecologists, etc. Thus, the challenge of lack of adequate funding has ripple effects on manpower and the caliber of expertise involved in the implementation process.

Accordingly, prominent among the issues that have over the years impeded adequate implementation and compliance with the CBD in Ghana include the weak capacity of relevant State institutions and lack of adequate resources to cover operation costs. Consequently, activities that adversely impact on biodiversity, such as illegal mining and logging activities, farming over hillsides and river banks, as well as bushfires in forest areas remain mostly uncontrolled due to the lack of capacity on the State institutions to act to prevent these incidences.

\subsection{The Complex Nature of Implementing MEAs in Ghana}

According to Article 73 of the 1992 Constitution of Ghana, "the Government of Ghana shall conduct its international affairs in consonance with the accepted principles of public international law and diplomacy in a manner consistent with the national interest of Ghana." Article 75(1) authorizes the President to "execute or cause to be executed treaties, agreements or conventions in the name of Ghana." However, Article 75(2) demands that prior to execution, all treaties or conventions "shall be subject to ratification" either by an "Act of Parliament" or "a resolution of Parliament supported by the votes of more than one-half of all the members of Parliament." The implication is that there is almost always likely to be delays in the execution of international treaties and conventions due to the nature of partisan politics in the country's Parliament. Besides, the nature of the country's decentralized local government system (as stipulated in Chapter 20 of the 1992 Constitution of Ghana: Decentralisation and Local Government [Articles 240-256]) does not make it any easier. Thus even ratified MEAs might still face implementation deadlocks at the lower levels of administration, and this is what usually happens to most projects that are directly related to the CBD. The fact is that seeking Parliamentary approval and ratification for the CBD was relatively easier than the actual implementation in some of the communities due to the long structures and multiplicity of institutions involved in the whole process.

One other major difficulty in implementing the CBD in Ghana stems from the challenge of identifying the needs of the different social groups and their different aspirations and priorities for biodiversity issues. Thus, whereas folks in the in the rural communities may be predominantly anxious about regular access to natural resources and ecosystem services that directly impacts their daily lives, such as access to clean water, good and constant crop yield, as well as fertile grazing land, and firewood for domestic use, the urban population may be concerned with constant energy, water, effective sanitation and waste management, while businesses may be interested in making money out of these resources. The rural communities may also focus on mining, logging, sand winning, etc all of which have consequences for the environment and biodiversity. At the same time, the government also needs the revenue from these activities in order to provide some of the basic services that would make life comfortable for the citizenry. There is thus the problem of effective prioritization and maintaining the proper balance in meeting the international obligation and domestic demands, as well as the interest of the several stakeholders involved. Hence there is the problem of what policy analyst have referred to as the complexity of joint action. (Pressman \& Wildavsky, 1984) Closely related to this challenge is the issue of lack of local ownership of the CBD in most local areas.

\subsection{Lack of Adequate Publicity on the Essence of the CBD}

Though efforts are been made at different levels of the Ghanaian society to conscientise people about the relevance of proper and sustainable use of biodiversity, the media coverage given to the subject is still woefully 
inadequate. Thus people do not really have enough information and understanding about the subject. The result is the usual pursuit of their immediate needs at the detriment of the environment. This attitude makes it much more difficult for institutions and agencies to really achieve targeted objectives regarding the CBD.

\section{Recommendations for Mitigating Implementation Challenges}

\subsection{Effective Engagement and Involvement with Civil Society}

To ensure the effective implementation of government policy initiatives regarding the targets of the CBD, there is the need to work with civil society movements across the broad society. This stems from the fact that studies have over the years indicated that across the globe, CSOs are usually a key component in educating the populace and enhancing the capabilities as well as participations in the overall development agenda. (Botchway, 2019a; 2018) Thus their effective engagement by the State in the implementation process would have a lot of positive implications for the entire process in the long run. Civil society organisations are important entities that ensure capacity building of various stakeholders and institutions. They are also able to bring on board various interest groups whose engagement may be beneficial for the effective implementation of the CBD both at the domestic and international levels. Effective engagement of CSOs could also lead to the situation where they may be able to fill some gaps in the provision of essential services to the communities where policies are been implemented.

\subsection{Enhancing Alternative Livelihood Projects (EnALPS)}

The current vicious threats to biodiversity coupled with the ever-competing demands for land and natural resources exploitation, calls for the effective and efficient targeting of conservation resources so as to ensure the effective and balanced implementation of the tenets of the CBD in Ghana. It is thus recommended that more alternative livelihood projects (ALPs) should be implemented and these should be done in locations that are most needed. In addition, already existing ALPs should be boosted by way of increasing the incentives and motivation packages. Such projects should not just target the provision of monthly allowances for subsistence, but must include activities and training programmes that can make the beneficiaries more independent financially in the long term by endowing them with skills that would benefit them for a lifetime.

Biodiversity is essential for humans' mutual agenda for sustainable development and existence and as such, there is the need to be better prepared to develop vigorous, comprehensible and well-coordinated solutions that can effectively lessen dangers to life and the environment that sustains it in general. The spate of recent degradation of ecosystems calls for serious reflections upon human values and environmental policies that would enhance the reduction of the rate at which biodiversity is being diminished. Consequently, the government as well as all stakeholders must ensure that interventions and policies implemented in the name of biodiversity do not compound public health and conservation challenges. Thus, there is the need to do an in-depth analysis of every proposed policy aimed at safeguarding the environment and the tenets of the CBD. There must also be timely monitoring, evaluation, and re-evaluation of all solutions and projects.

There should be more concerted efforts to lessen the adverse environmental impacts of fishing, farming and mining, thus supporting environmental integration, and consequently reconciling agriculture with the objectives of the CBD in a more practical manner. For instance, in order to regulate overfishing and the fishing of endangered marine species, the country can promote and encourage more local fishermen and fishing communities to go into fish farming. There is also the need to intensify public awareness, sensitization, and education since the effective implementation of the CBD has everything to do with "the perceptions and behavior of people" and the pressures they exert on "biological diversity." (European Communities, 2008, p. 24)

\subsection{Avoidance of One-Size-Fits-All Solutions}

Attempts aimed at formulating universal political and economic plans in dealing with environmental problems though may seem worthwhile must however be given a second thought. Thus, instead of implementing a one-size-fits-all policy, efforts should be made at encouraging case-by-case analysis and specific area and country solutions. There is also the need to aim at increasing awareness and the discussion of the complex ethical dilemmas that confronts balancing societal needs and the utilization of the natural environment. There is the need to identify useful scientific data, as well as available ethical frameworks of values and principles for policy options that have proven valuable in facing the challenges in other regions and countries.

Moreover, in order to enhance efficiency in the decision-making process, as far as biodiversity and the environment are concerned, decision makers and duty bearers must study and evaluate different "spatial plans and related sector development scenarios, Strategic Environmental Assessment (SEA)" - a holistic and systemic approach that favors the pro-active consideration of environmental issues in planning and decision making. It thus sanctions the evaluation of cumulative environmental impacts of Policies, Plans and Programs. There is also 
the need for EIA and community mapping that supports the visualization and integration of environmental and socio-economic information across time and space at different scales. (SCBD, 2010, p. 43)

There is the need to improve the dynamics between humans and the numerous species that conglomerate in creating the environment. This improvement will in the long run be beneficial to all living things. Moreover, preserving traditional knowledge that is usually related to the preservation and sustainable use of biodiversity in specific areas is very important. Thus, it is recommended that the government must create a national inventory on traditional knowledge. This inventory will be vital for understanding indigenous communities and the related knowledge which will in turn help fine-tuning targeted programmes and result-oriented policies for effective implementation of the CBD.

\subsection{Building Human, Technical and Institutional Capacities}

There is the need to build human, as well as technical, and institutional capacities at both the local and national levels to ensure that a vibrant foundation exists for the effective conservation and sustainable use of biodiversity. This could be in the form of strengthening existing institutions to enhance their various roles, training individuals to monitor and assess biodiversity, supporting all-embracing sustainable-use-oriented activities and refining systems of protected areas. Periodic training should be organized for individuals and entities involved in the implementation of the country's CBD targets. Such training should focus on the practical issues of biodiversity, the CBD and related matters. When necessary, the stakeholders in the training should be taken into the relevant fields to have practical knowledge and essence of the issues being discussed.

There should be in place proactive measures to minimize illegal exploitation and degradation of the already depleting ecological resources in the country. There is the need for the country to take stock and identify the many options for improving biodiversity conservation. Policy makers and duty-bearers must also define clear-cut national biodiversity strategies as well as appropriate action plans for implementation at various levels. In addition, all the necessary efforts must be made to ensure the incorporation of biodiversity related issues into environmental impact assessment legislations in the country. Thus, the relevant institutions must undertake case-studies on ongoing practices in environmental impact assessment and strategic environmental assessment procedures and monitor them keenly to ensure positive outcomes that are replicable in other areas and activities when necessary.

The various institutions mandated with the responsibility to ensure the effective implementation of the tenets of the CBD must continuously fine-tune and overhaul procedures and also develop programmes in response to emerging issues. This thus calls for pro-activeness on the part of all stakeholders. The point is that without adequate instruments, it will be difficult to implement the CBD even when the political motivation and needed resources are available. Thus, as other studies have indicated, the incorporation of biodiversity concerns in existing practices, such as urban design projects or redevelopment plans is a necessity to ensuring the achievement of the CBD targets in any society. (United Nations University, 2010)

There is the need to translate scientific knowledge into socio-economic benefits. By so doing, the targets of the CBD will be met while at the same time imparting positively on poverty reduction efforts. In addition, there is the need to involve staff of the Ministry of Finance in planning biodiversity related projects. This would equip them with adequate information on the nature and relevance of environmental investments and their economic benefits. Their involvement and consequent understanding would eventually help reduce the protracted under-funding that usually characterizes environmental programmes and investments in the country.

\subsection{Strategic Courting of International Development Partners}

There is the need for greater and enhanced international support and collaboration in the creation and maintenance of local monitoring capacity. Thus, duty bearers and implementing agencies as well as the Government of Ghana must make all the necessary efforts to establish strong and formidable relations with international networks that promote biodiversity conservation such as the Metropolis Association, the Urban Biosphere Group constituted under the UNESCO Man and Biosphere programme (MAB), and the Global Partnership for Cities and Biodiversity, etc.

The Government of Ghana must also make conscientious efforts aimed at having a better understanding about the role of the environment in development policies, as well as establish effective budgeting processes that prioritizes environmental policies and enhances the achievement of the objectives of the CBD. In this regard, over dependence on donors and the so-called development partners for dealing with sustainable development and CBD related matters must be reduced to the barest minimum. The State must put in place proper measures to have adequate funding for biodiversity-related matters - donor support should only be a last resort and mean 
what it is meant to be - support. It should be a strategic partnership; not a dependence relation.

\subsection{Enforcement of Punitive and Preventive Measures}

It is recommended that the State should formulate more and effective punitive measures that may impose both preventive and remedial measures on enemies of biodiversity. These measures may range from the levying of heavy compensation, closure of encroaching entities, to habitat restoration at the original, or at an equivalent site. There should also be in place effective polluter pay policies to target activities that destroy biodiversity and the environment. The point is that, with regards to environmental damage and liability, it is usually argued that if the laws of the land provides for civil and criminal sanctions, then accordingly courts will be able to apply the rules. However, where there are no sanctions and penalties for noncompliance, the courts are unlikely to do anything. (UNESCO, 2011) Thus the existence of principles such as the 'polluter pays principle' and the 'absolute liability principle' are effective ways of ensuring compliance with environmental laws and hence meeting the goals of the CBD. Consequently, environmental laws must be enforced with criminal sanctions for non-compliance. This implies that violations must be meted with imprisonment or fines as may seem appropriate. In addition, in cases where an organization is involved, the individual in charge at the time and the corporation itself must be found guilty of their offence. This if done properly and timely will serve as a deterrent for other organizations and individuals.

As several studies have indicated, in order to prevent or modify developments that will have adverse impacts on biological diversity, an effective system of environmental impact assessment is deemed necessary. Thus, there is the need to put into place effective and comprehensive assessment measures to identify projects that are of high risk to biodiversity, as identified by Article 14 of the CBD. Accordingly, activities within protected areas must be designed to strengthen management and administrative capacities so as to develop additional supportive legal foundation aimed at increasing stakeholder awareness of biodiversity conservation, promoting alternate livelihoods, and also improving cooperation between national and local authorities.

\subsection{Implementation of Finance-Generating Biodiversity Services}

There is the need for the introduction of Environmental Fiscal Reform (EFR) - a system of "taxation and pricing measures" which are aimed at raising "fiscal revenues while furthering environmental goals." The argument is that EFR affords added monetary benefits and also promotes sustainability and poverty reduction, especially for developing countries. Thus, EFR while protecting natural resources from dilapidation, also leads to the generation of financial returns that would be essential for pro-poor investments. EFR will consequently serve as a measure for strengthening legal and regulatory approaches for environmental management in the long run. (SCBD, 2010; OECD, 2009; 2005)

It must however be noted that since development planning and decision making usually favor rapid growth over sustainability, and since there has been increasing challenges to the capacity of ecosystems to adjust and regenerate the desired goods and related services (SCBD, 2010), embarking on the proposed finance-generating biodiversity services should be done in a very cautious manner. It is thus imperative that any measure that seeks to promote sustainable development and for that matter the conservation of biodiversity should respect the limits of ecosystem resilience as well as the effective regeneration of its constituents. There is therefore the need for the Government of Ghana to add an "environmental lens" to the decision making process since this is essential for avoiding long term and irreversible impacts of people's activities on biodiversity. (SCBD, 2010, p. 11)

More efforts should be made to ensure the effective and efficient management and protection of the country's lingering permanent estate of forest reserves and wildlife reserves. With the gradual loss of the off-reserve shield, failure to improve the management and protection of the reserves and protected areas would only mean vulnerability to both legal and illegal encroachment in the near future.

\subsection{Building Consensus Among Stakeholders}

Over the years, one major factor that has hindered the significance of maintaining environmental sustainability in most countries, aside the need to achieve rapid economic returns is the issue of conflicting sector priorities. For that reason, any attempts at integrating environmental dimensions into various sectors' objectives and impact analyses would require a strong understating of the objectives and impacts of other sectors. This when properly handled will reduce the challenges related with the complexity of joint action.

Since the management and use of natural resources in any country commonly implies the involvement of different stakeholders that often have conflicting interests, in order to be successful, environmental policies have to be accepted by all the concerned players. Since these individuals and groups can play an influential role in determining the overall use of ecosystems and biodiversity, an unbalanced or narrow application of their policies 
and governing powers on ecosystem uses may affect poor communities, while corruption and vested interests reinforce the marginalization of the poor. (SCBD, 2010)

The point must also be emphasized that "decentralization and local empowerment are not always a guarantee for environmental stewardship." Thus, any fanatic misconception of "community empowerment as the panacea for poverty alleviation and environmental protection" must be avoided. (World Bank, 2002) In addition, the promotion of a resilient decentralization process should not in any way imply a "total disconnection from central planning." (SCBD, 2010, p. 45) It should rather lead to the definitive identification of the role of all stakeholders including the local, regional and central authorities as well as CSOs and private organizations. This would eventually enhance the avoidance of overlaps in responsibilities and obligations while at the same promoting vertical coherence and horizontal integration between the administrative levels and sector policies respectively.

If indeed we would agree with the assertion that biodiversity is "the natural capital, the stock of natural ecosystems, which provide valuable services for any human activity" (Government of Ghana (GoG), 2016, p. 2), then there is indeed no other way than to put in place effective measures to regulate their use, maintain their health, sustain their linkages. We would also appreciate the fact that our very existence is linked to the existence of this biological diversity - we are actually part of it as humans and this implies our sustainable use. This is notwithstanding the point that the value of biodiversity to the human race cannot be entirely estimated.

\section{Conclusion}

As a responsible member of the international community, Ghana has over the years been making several efforts to implement its international obligation under the United Nations' CBD which the country ratified on August 29, 1994. However, with regards to forestry and wildlife policies, it has been argued that earlier wildlife policies in Ghana which were based upon the idea of the "conservation and sustainable development of the nation's forest and wildlife resources for maintenance of environmental quality and perpetual flow of optimum benefits to all segments of society" (Government of Ghana (GoG), 1994, p. 8) and "the ability of the state to control the behavior of either market participants or rural populations" is no longer valid since there is inadequate evidence to ascertain that the centralized agencies mandated for wildlife and forestry protection are able to "control access to, and exploitation of, forest and wildlife resources." The point is that illegal and chainsaw logging, as well as bushmeat hunting is still uninhibited in the country. Thus, the State, it is argued, "by assuming authority for these resources without the capacity to exercise its responsibilities, has created at best an open access system." (World Bank, 2006, p. 34) In short, several challenges persist in the country's efforts at environmental protection and sustainable development which are key elements of the CBD to which it is a party. It is some of these challenges that this study sought to identify and recommend some relevant measures to mitigate. The study is of the view that if the recommended measures are keenly adhered to, it will lead to the eventual enjoyment of the full benefits of biodiversity without necessarily destroying them and causing harm to the environment indiscriminately.

In light of the foregoing discussion, it will be quite appropriate to agree with UNESCO's observation that "the foundation of a successful biodiversity management regime is careful and systematic planning, which requires a comprehensive framework of laws that clarifies responsibilities, obligations and procedures." And that "there is no one overarching biodiversity management regime that will be able to be successfully applied in all countries due to the cultural, political and economic differences that exist within the different jurisdictions." (UNESCO, 2011, p. 69).

\section{References}

Adutwum, R. O. (2010, September 23). Ghana's Progress Towards The Achievement Of The MDGs. Retrieved Febuary 26, 2019, from http://slidegur.com/doc/1060861/ghana-s-progress-towards-the-achievement-of-the-mdgs

Botchway, T. P. (2018). Civil Society and the Consolidation of Democracy in Ghana's Fourth Republic. Cogent Social Sciences, 4(1), 1-17. https://doi.org/10.1080/23311886.2018.1452840

Botchway, T. P. (2019a). Understanding the Dynamics and Operations of Civil Society in the 21st Century: A Literature Review. Journal of Politics and Law, 12(1), 108-121. https://doi.org/10.5539/jpl.v12n1p108

Botchway, T. P. (2019b). The Balanced Obligation and the Basis for Compliance in International Law: Reflections on the Question of International Obligation. Journal of Politics and Law, 12(2).

CBD Secretariat. (n.d.). Ghana - Country Profile. Retrieved November 1, 2018, from https://www.cbd.int/countries/profile/default.shtml? country=gh\#facts 
European Communities. (2008). The Convention on Biological Diversity Implementation in the European Union (Update 2008). European Commission.

Government of Ghana (GoG). (1994). Republic of Ghana: Forest and Wildlife Policy. Accra: Ministry of Lands and Forestry.

Government of Ghana (GoG). (2016, November). National Biodiversity Strategy and Action Plan. Accra: Ministry of Environment, Science, Technology and Innovation (MESTI).

Government of Ghana (GoG). (2017). The 2018 Budget Statement and Economic Policy of Government: "Putting Ghana Back to Work". Accra: Ministry of Finance and Economic Planning.

Hackman, K. O. (2014). The state of biodiversity in Ghana: Knowledge gaps and prioritization. International Journal of Biodiversity and Conservation, 6(9), 681-701. Retrieved from http://www.academicjournals.org/IJBC

International Monetary Fund (IMF). (2012). Ghana: Poverty Reduction Strategy Paper. Washington, D.C.: IMF. https://doi.org/10.5089/9781475506129.002

Interview, I. R. (2018, December 15). Interview with International Relations and Global Environmental Governance Expert on the Implementation of CBD in Ghana. (First Author, Interviewer)

Interview, P. P. (2018, December 16). Interview with Public Policy Expert. (First Author, Interviewer)

Kaufman, H. (1973). Administrative Feedback. Washington DC: Brookings Institution.

Lester, J. P., Bowman, A. O., Goggin, M. L., \& Laurence J. O'Toole, J. (1987). Public Policy Implementation: Evolution of the Field and Agenda for Future Resaerch. Policy Studies Review, 7(1), 200-216. https://doi.org/10.1111/j.1541-1338.1987.tb00038.x

Mazmanian, D. A., \& Sabastier, P. A. (1983). Implementation and Public Policy. Chicago: Scott Foresman \& Co.

Ministry of Environment and Science (MoES). (2002). National Biodiversity Strategy for Ghana. Accra: Ministry of Environment and Science.

Ministry of Environment, Science and Technology (MEST). (2011). Response to Questionnaire on Implementation of Sustainable Development Agenda Submitted by the Government of Ghana to the United Nations Commission on Sustainable Development (UNCSD). Accra: Ministry of Environment, Science and Technology.

Okley, B. L. (2004). Legislation and Implementation of International Environmental Law by African Countries: a Case Study of Ghana. University of Georgia, School of Law. Athens: Student Works and Organizations at Digital Commons @ Georgia Law. Retrieved from http://digitalcommons.law.uga.edu/stu_llm/38

Organization for Economic Co-operation and Development (OECD). (2005). Environmental Fiscal Reform for Poverty Reduction. Paris: Organization for Economic Co-operation and Development .

Organization for Economic Co-operation and Development (OECD). (2009). Natural Resources and Pro-Poor Growth: The Economics and Politics, DAC Guidelines and Reference Series - A Good Practice Paper. Paris: OECD Publishing.

Paudel, N. R. (2009). A Critical Account of Policy Implementation Theories: Status and Reconsideration. Nepalese Journal of Public Policy and Governance, xxv(2), 36-54.

Pressman, J. L., \& Wildavsky, A. (1973). Implementation: How Great Expectation in Washington are Dashed in OakLand; Or, Why It's Amazing that Federal Programs Work at All. Berkeley: University of California Press.

Pressman, J. L., \& Wildavsky, A. (1984). Implementation (3rd ed.). California: University of California Press.

Secretariat of the Convention on Biological Diversity (SCBD). (2010). Ecosystem Goods and Services in Development Planning: A Good Practice Guide. Montreal: Secretariat of the Convention on Biological Diversity.

UNESCO. (2011). Ethics and Biodiversity. Bangkok: UNESCO.

United Nations University. (2010). Cities, Biodiversity and Governance: Perspectives and Challenges of the Implementation of the Convention on Biological Diversity at the City Level. Pacifico-Yokohama: United Nations University. 
Von Meter, D. S., \& Van Horn, C. E. (1975). The Policy Implementation Process. Administration and Society, 6(4), 445-488. https://doi.org/10.1177/009539977500600404

World Bank. (2002). A Sourcebook for Poverty Reduction Strategies; Core techniques and cross-cutting issues (Vol. 1). Washington DC, USA: World Bank.

World Bank. (2006). Ghana: Country Environmental Analysis. Washington, D.C.: World Bank.

\section{Note}

Note 1. This paper is an expanded version of a chapter in a thesis submitted by the first author (with valuable addition by the second author). The overall project examines the implementation of sustainable development policies under multilateral environmental agreements, their theoretical and practical implications for States and practitioners, as well as the challenges and prospects involved in such endeavours.

\section{Copyrights}

Copyright for this article is retained by the author(s), with first publication rights granted to the journal.

This is an open-access article distributed under the terms and conditions of the Creative Commons Attribution license (http://creativecommons.org/licenses/by/4.0/). 